\title{
Absorbing aerosols at high relative humidity: linking hygroscopic growth to optical properties
}

\author{
J. Michel Flores ${ }^{1,2,{ }^{*}, \text { R. Z. Bar-Or }}{ }^{3}$, N. Bluvshtein ${ }^{3}$, A. Abo-Riziq ${ }^{3}$, A. Kostinski ${ }^{4}$, S. Borrmann ${ }^{1,2}$, I. Koren ${ }^{3}$, \\ I. Koren ${ }^{3}$, and Y. Rudich ${ }^{3}$ \\ ${ }^{1}$ Max Planck Institute for Chemistry, Particle Chemistry Department, Mainz, Germany \\ ${ }^{2}$ University of Mainz, Institute for Atmospheric Physics, Mainz, Germany \\ ${ }^{3}$ Weizmann Institute of Science, Environmental Science Department, Rehovot, Israel \\ ${ }^{4}$ Department of Physics, Michigan Technological University, Houghton, Michigan, USA \\ *now at: Weizmann Institute of Science, Environmental Science Department, Rehovot, Israel
}

Correspondence to: Y. Rudich (yinon.rudich@weizmann.ac.il)

Received: 10 November 2011 - Published in Atmos. Chem. Phys. Discuss.: 11 January 2012

Revised: 10 May 2012 - Accepted: 1 June 2012 - Published: 25 June 2012

\begin{abstract}
One of the major uncertainties in the understanding of Earth's climate system is the interaction between solar radiation and aerosols in the atmosphere. Aerosols exposed to high humidity will change their chemical, physical, and optical properties due to their increased water content. To model hydrated aerosols, atmospheric chemistry and climate models often use the volume weighted mixing rule to predict the complex refractive index (RI) of aerosols when they interact with high relative humidity, and, in general, assume homogeneous mixing. This study explores the validity of these assumptions. A humidified cavity ring down aerosol spectrometer (CRD-AS) and a tandem hygroscopic DMA (differential mobility analyzer) are used to measure the extinction coefficient and hygroscopic growth factors of humidified aerosols, respectively. The measurements are performed at $80 \%$ and $90 \% \mathrm{RH}$ at wavelengths of $532 \mathrm{~nm}$ and $355 \mathrm{~nm}$ using size-selected aerosols with different degrees of absorption; from purely scattering to highly absorbing particles. The ratio of the humidified to the dry extinction coefficients $\left(f \mathrm{RH}_{\mathrm{ext}}(\% \mathrm{RH}\right.$, Dry $\left.)\right)$ is measured and compared to theoretical calculations based on Mie theory. Using the measured hygroscopic growth factors and assuming homogeneous mixing, the expected RIs using the volume weighted mixing rule are compared to the RIs derived from the extinction measurements.

We found a weak linear dependence or no dependence of $f \mathrm{RH}(\% \mathrm{RH}$, Dry) with size for hydrated absorbing aerosols in contrast to the non-monotonically decreasing behavior
\end{abstract}

with size for purely scattering aerosols. No discernible difference could be made between the two wavelengths used. Less than $7 \%$ differences were found between the real parts of the complex refractive indices derived and those calculated using the volume weighted mixing rule, and the imaginary parts had up to a $20 \%$ difference. However, for substances with growth factor less than 1.15 the volume weighted mixing rule assumption needs to be taken with caution as the imaginary part of the complex RI can be underestimated.

\section{Introduction}

A major uncertainty in understanding Earth's climate system is the interaction between solar radiation and aerosols in the atmosphere. This interaction is dependent on the physical and chemical properties of the aerosols and the wavelength of the incident light. Aerosols can scatter and absorb shortwave (solar) radiation, and therefore changes in the their atmospheric concentrations and/or their chemical, and physical properties can alter the energy balance of the climate system and are drivers of climate change (IPCC, 2007). The resulting positive or negative changes in the energy balance due to these factors are expressed as radiative forcing; the last report from the Intergovernmental Panel on Climate Change (IPCC) showed that, to a great extent, aerosols have a cooling effect (Forster et al., 2007). However, our level of scientific understanding of the radiative forcing effects of aerosols 
in the atmosphere is still low. Specifically, the role of light absorbing aerosols is poorly understood, as they transform electromagnetic radiation into thermal energy thereby changing the temperature profiles of their surroundings and reducing the incident solar flux/radiation below the absorbing aerosols (Schwartz and Buseck, 2000; Streets et al., 2006). The heating caused by the aerosols can cause a positive topof-atmosphere radiative forcing (Tripathi et al., 2005) if they decrease the planetary albedo (as seen from space) or if their single scattering albedo (SSA) is lower than the surface or the clouds below them. Recently, there is more evidence that carbonaceous aerosols are much more dominant and widespread in the atmosphere than previously thought (Novakov et al., 1997; Petzold et al., 2007; Reddy et al., 2005). Consequently, measuring and deriving their optical properties is critical in calculating the effects of aerosols on radiative transfer.

Furthermore, there is a complex interaction between clouds, aerosols and radiation that is still not well constrained. For example, Koren et al. (2007) showed that a belt of forming and evaporating cloud fragments and hydrated aerosols, extending kilometers away from the clouds into cloud-free areas could, have major implications on the estimation of Earth's radiation budget. This phenomenon has been termed the "twilight zone". In the twilight zone, high relative humidity $(\mathrm{RH})$ is predominant, creating an environment where aerosols can take up water and eventually deliquesce, grow, and become more optically active. Also, cloud droplets evaporating in this region can leave behind concentrated solution droplets and processed aerosol particles with complex chemical compositions and sizes with enhanced optical effects.

To attempt to calculate the climatic effects of different species found in the atmosphere, researches have used chemical transport models for many years. By first assuming a complex refractive index (RI) and physical properties of the aerosols (size, shape and state of mixing), most climate modelers obtain scattering and absorption cross sections, and apply those properties to modeled concentrations (Bond and Bergstrom, 2006). The complex RI $(m=n+i k)$ describes the scattering (real part, $n$ ) and absorption (imaginary part, $k$ ) efficiencies of a substance. At different RH values, water uptake by atmospheric aerosols can occur, altering their size and composition. This, in turn, changes the complex refractive index of the aerosols. To accurately predict the "new" complex RI different theoretical mixing rules are often used (Erlick, 2006). The most common rule is the volume weighted mixing rule, which is often used in chemical transport models that estimate the aerosol direct forcing (Haywood et al., 1997; Liu et al., 2007b), and in laboratory studies. Abo Riziq et al. (2007) measured different organic mixtures to test the validity of this mixing rule for a solution. Garland et al. (2007) used the volume weighted mixing rule (assuming complete mixing of the aerosols as they passed through a humidification stage) to test the performance of their system and to parameterize the change in the extinction coefficient when purely scattering substances (inorganic and organic) were exposed to an RH of $80 \%$.

Some laboratory studies have been devoted to understanding the optical properties of purely scattering aerosols (mostly due to their "cooling effect") when exposed to high relative humidity. Garland et al. (2007) parameterized the relative humidity dependence of light extinction at $532 \mathrm{~nm}$ for inorganic ammonium sulfate aerosols, Baynard et al. (2006) looked at mixtures of $\mathrm{NaCl}$ and ammonium sulfate with a few dicarboxylic acids, and Fierz-Schmidhauser et al. (2010) measured the scattering dependence of ammonium sulfate and sodium chloride. Conversely, we could only find two recent studies (Hasenkopf et al., 2011; Lewis et al., 2009) which dealt with the optical growth of slightly absorbing particles. Hasenkopf et al. (2011) focused on the optical growth at $532 \mathrm{~nm}$ of organic particles likely to have been present on early Earth and Titan, and Lewis et al. (2009) studied the scattering and absorption increase (or reduction) at 530 and $870 \mathrm{~nm}$ using three different types of smoke particles.

In this study, we explore the validity of the volume weighted mixing rule for water soluble absorbing aerosols, and address the change in the refractive index of absorbing aerosols when exposed to $80 \%$ and $90 \%$ relative humidity values, at wavelengths of $355 \mathrm{~nm}$ and $532 \mathrm{~nm}$. By doing so, we attempt to link measured hygroscopic growth (by tandem hygroscopic DMA measurements), measured extinction (by cavity ring down aerosol spectroscopy) and model calculations in order to estimate their ability to predict the optical properties of hydrated aerosols with different absorption extents. Moreover, we investigate how does the ratio of the extinction coefficient of the humidified aerosols to the dry extinction coefficient change as a function of size. We also test a core-shell structure model to explore the differences between the models for substances with low growth factors under these hydration conditions.

\section{Methodology}

\subsection{Aerosol optical extinction measurements}

To study the RH dependence of aerosols' optical extinction at 532 and $355 \mathrm{~nm}$, a cavity ring down aerosol spectrometer (CRD-AS), and a scanning mobility particle sizer (SMPS; TSI model 3081) were used. A schematic of the laboratory setup is shown in Fig. 1. A full description of the CRD-AS used in this study can be found in Abo Riziq et al. (2007). Briefly, two plano-concave highly reflective mirrors (Los Gatos) are mounted at both ends of a stainless steel tube. The third harmonic $(355 \mathrm{~nm})$ or the second harmonic $(532 \mathrm{~nm})$ of an Nd:YAG laser $(10 \mathrm{~Hz}, 3-6 \mathrm{~ns}$, Ekspla) are introduced into the cavity through one end, the pulse of light in the cavity bounces back and forth, and by placing a photomultiplier at the other end of the cavity, the intensity of the light exiting the cavity is measured. The time it takes the 


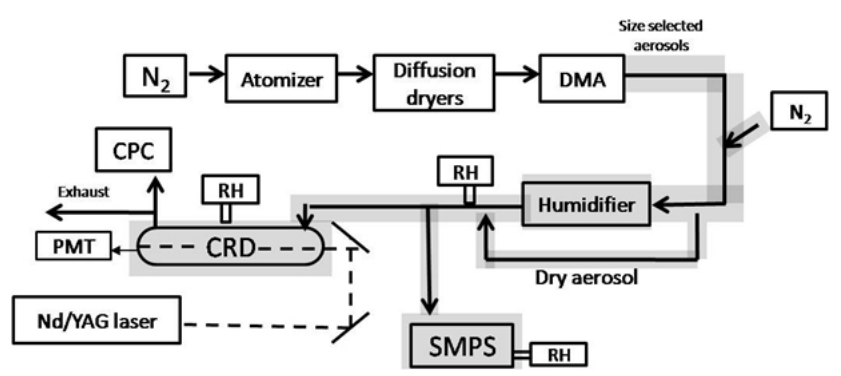

Fig. 1. Schematic presentation of the laboratory setup. The bold arrows show the aerosol flow and the dotted lines represent the laser's light paths. The temperature and relative humidity meters are marked as "RH". Abbreviations: CPC, condensation particle counter; PMT, photomultiplier; DMA, differential mobility analyzer.

initial intensity of the light to decay to $1 / e$ is then measured. By measuring the empty cavity (filled only with the carrier gas) decay time $\left(\tau_{o}\right)$ and the decay time filled with aerosols $(\tau)$, the extinction coefficient (extinction $=$ scattering $+a b-$ sorption) can be directly measured (Pettersson et al., 2004; Abo Riziq et al., 2007):

$\alpha_{\mathrm{ext}}=\frac{L}{c d}\left[\frac{1}{\tau}-\frac{1}{\tau_{o}}\right]$

where $L$ is the length of the cavity, $d$ is the distance filled with aerosols, and $c$ is the speed of light.

For homogeneous spheres, the extinction coefficient $\left(\alpha_{\text {ext }}\right)$ is described by:

$\alpha_{\text {ext }}=N \sigma_{\text {ext }}=\frac{1}{4} \pi N D^{2} Q_{\text {ext }}$

where $\sigma_{\text {ext }}$ is the extinction cross section, $N$ is the particle concentration, $D$ the particle diameter, and $Q_{\text {ext }}$ the extinction efficiency (which is the ratio of the optical extinction cross section to the geometric area of the particle). The extinction efficiency at a given wavelength and RI is only a function of the particle size. The particle size is normally expressed as a dimensionless size parameter $(x)$, which is the ratio of the particle circumference to the wavelength $(\lambda)$ of the incident light $(x=\pi D / \lambda)$. The RI of aerosols can then be retrieved by using Mie theory and finding the theoretical $Q_{\text {ext }}$ curve that best fits the measured $Q_{\text {ext }}$ values for the different aerosol size parameters measured.

The retrieval algorithm described in Abo Rizq et al. (2007) was used to retrieve the complex refractive indices. The algorithm simultaneously varies $n$ and $k$ and scans through all physically possible values of the complex RI within a chosen resolution until it minimizes $\chi^{2}$ :

$\chi^{2}(n, k)=\sum_{i=1}^{N_{\mathrm{d}}} \frac{\left(Q_{\text {ext measured }}-Q_{\text {ext calculated }}(n, k)\right)_{i}^{2}}{\varepsilon_{i}^{2}}$

where $N_{\mathrm{d}}$ is the number of diameters measured, and $\varepsilon$ is the estimated error in the measurement. To estimate the retrieval uncertainties in $n$ and $k$ ( $\Delta n$ and $\Delta k$ ), it is assumed that the standard deviations of the measurements are normally distributed, and that the values of $\chi^{2}$ follow a $\chi^{2}$-distribution for the two degrees of freedom, $n$ and $k$. The algorithm returns the values of $n$ and $k$ that satisfy $\chi_{0}^{2} \leq \chi^{2} \leq \chi_{0}^{2}+2.298$ where the value 2.298 denotes the $1 \sigma$ deviation from the minimum $\chi^{2}\left(\chi_{0}^{2}\right)$. Miles et al. (2010) showed that the accuracy in the retrieval of the real part of the RI has a minimum error of $-0.5 \%$ and $+0.3 \%$, to account for this error we've added an additional $1 \%$ error to the retrieval uncertainties.

\subsection{Aerosol generation and humidification}

Aerosols were generated by atomizing aqueous solutions of the compounds of interest with a TSI constant output atomizer (TSI-3076, $35 \mathrm{psi}, 2.5$ standard liters per minute (SLM) flow), the aerosol population is subsequently dried ( $\mathrm{RH}<3 \%$ ), passed through a neutralizer (TSI 3012A) to obtain an equilibrium charge distribution on the particles, and size selected with a differential mobility analyzer (DMA, TSI model 3081) to obtain a quasi-monodisperse particle distribution. The dry, size selected aerosols exiting the DMA were diluted and directed to a deliquescence stage consisting of a saturated permeable membrane at a controlled temperature before being sampled by the CRD-AS and scanning mobility particle sizer (SMPS; TSI 3080) system. Aerosol losses were measured with polystyrene latex spheres of different sizes (from $200 \mathrm{~nm}$ up to $800 \mathrm{~nm}$ ) by placing a condensation particle counter (CPC; TSI Model 3022A) before the CRD-AS, and comparing the particle number concentration of this CPC with another CPC located at the end of the system; differences in particle concentration of less than $2 \%$ were found. To avoid temperature fluctuations in the system, insulation was placed around the tubing, the CRD-AS, and SMPS (represented by the shaded areas in Fig. 1). The relative humidity and temperature were measured at the exit of the humidification stage, within the CRD-AS, and at the entrance of the sheath flow of the DMA in the SMPS system. Measurements were only taken when all measured $\mathrm{RH}$ values in the system were within $2 \%$ (RH meter manufacture uncertainties are $\pm 3 \% \mathrm{RH}$ for $10 \leq \% \mathrm{RH} \leq 90$ ). Following the deliquescence stage the aerosols' RH dependent extinction coefficient $\left(\alpha_{\text {ext, } \% \text { RH }}\right)$ was measured with the CRD-AS, and the hygroscopic growth factor (GF) was measured with the SMPS. The aerosol number concentrations were also measured with a CPC at the outlet of the CRD-AS.

Aerosols were measured at eight different initial mobility diameters, from 200 to $550 \mathrm{~nm}$ in $50 \mathrm{~nm}$ steps, and two different RH values; $80 \%$ and $90 \%$. The sequence of measurements was performed by first measuring the diameter of an aerosol in a dry state $(\mathrm{RH}<3 \%)$, then directing the sample flow through the humidifier, allowing the system to equilibrate at the desired $\mathrm{RH}$, and repeating the measurement for the same initial diameter. After the hydrated experiments, the dry measurement was repeated to check the stability of the 
system. To ensure experimental stability, the measurements were repeated if the final dry extinction cross section differed by more than $5 \%$ from the initial one. Furthermore, to estimate the contribution from doubly charged particles, SMPS scans of the dry polydisperse distributions entering the first DMA were taken.

\subsection{Multiple charge corrections}

For each selected mobility diameter, singly and multiply charged particles of the same mobility are also transmitted through the DMA. The multiply charged particles affect the optical measurements, leading to overestimation of the optical extinction cross section. To reduce biases arising from multiply charged particles we used a solution concentration of $500 \mathrm{mg} \mathrm{l}^{-1}$ for sizes between 200 to $300 \mathrm{~nm}$, and a $1000 \mathrm{mg}^{-1}$ solution for 350 to $550 \mathrm{~nm}$ diameter aerosol. We measured the resulting size distributions and using the Wiedensohler charge distribution parameterization (Wiedensohler, 1988 with subsequent erratum) found that at these solution concentrations, between $2.7-7 \%$ and up to $1 \%$ of doubly and triply charged particles, respectively exist in the flow. These percentages were used to correct for the contribution of multiply charged particles to the total extinction at each diameter using literature values of the complex refractive indices, when available (e.g. ammonium sulfate), and to correct the size distributions measured by the SMPS. When RI literature values were not available, only the size distributions were corrected. The median diameter from the corrected SMPS size distribution was taken as the measured diameter.

\subsection{Hygroscopic and optical growth calculations}

The hygroscopic growth is represented by the relative increase in the mobility diameter of particles due to water uptake at a specific \% RH:

$\mathrm{GF}(\% \mathrm{RH}, \mathrm{Dry})=\frac{D_{\% \mathrm{RH}}(\mathrm{RH})}{D_{\mathrm{dry}}}$

where $D \% \mathrm{RH}(\mathrm{RH})$ is the mobility diameter at a specific $\% \mathrm{RH}$, and $D_{\text {dry }}$ is the dry measured mobility diameter. The growth factor $(\mathrm{GF})$ of a mixture $\left(\mathrm{GF}_{\text {mix }}\right)$ can be estimated from the GFs of the pure components and their respective volume fractions $(\varepsilon)$ using the Zdanovskii-Stokes-Robinson relation (ZSR relation; Sjogren et al., 2007; Stokes and Robinson, 1966):

$\mathrm{GF}_{\text {mix }}=\left(\sum_{j} \varepsilon_{j} \mathrm{GF}_{j}^{3}\right)^{1 / 3}$

where the subscript $j$ represents the different substances. The model assumes spherical particles, ideal mixing (i.e. no volume change upon mixing) and independent water uptake of the organic and inorganic components.
The changes of the aerosols optical properties due to hygroscopic growth is represented by the ratio of the measured extinction coefficient $\left(\alpha_{\text {ext }}, \mathrm{Mm}^{-1}\right)$ at a specific $\% \mathrm{RH}$ to the dry measurement, expressed as:

$f \mathrm{RH}_{\mathrm{ext}}(\% \mathrm{RH}$, Dry $)=\frac{\alpha_{\text {ext }}(\% \mathrm{RH})}{\alpha_{\text {ext }}(\text { Dry })}$

where $\alpha_{\text {ext }}(\% \mathrm{RH})$ is the extinction coefficient at a specific $\mathrm{RH}$, and $\alpha_{\text {ext }}$ (Dry) is the extinction coefficient measured at an $\mathrm{RH}<3 \%$. Inserting Eqs. (2) and (3) into Eq. (5), the equation can be written as:

$f \mathrm{RH}_{\mathrm{ext}}(\% \mathrm{RH}$, Dry $)=\frac{N_{\% \mathrm{RH}} Q_{\text {ext}-\% \mathrm{RH}}}{N_{\text {Dry }} Q_{\text {ext-dry }}} \mathrm{GF}^{2}$

Three different substances were used to measure the dependence on size and degree of absorbance of the optical extinction growth, $f \mathrm{RH}_{\text {ext }}(\% \mathrm{RH}$, Dry): ammonium sulfate (AS), a purely scattering substance, was used to validate the system performance; nigrosine, an organic black dye used as a model for highly absorbing substances; and IHSS Pahokee Peat (Pahokee), a fulvic acid used as a model for humic-like substances, or complex organic matter often found in aerosol (Dinar et al., 2007). A mixture of ammonium sulfate and nigrosine at a molar ratio of 1:1 (AS:Nig), was also measured to investigate the variation in the imaginary part of the complex refractive index.

\section{System validation with ammonium sulfate}

The measurements of $f \mathrm{RH}_{\mathrm{ext}}(\% \mathrm{RH}$, Dry) with the system described above were validated with ammonium sulfate at $80 \% \mathrm{RH}$. Figure 2 compares the measured $f \mathrm{RH}_{\mathrm{ext}}(80 \% \mathrm{RH}$, Dry) in this study, to that reported by Garland et al. (2007) and to the $f \mathrm{RH}_{\mathrm{ext}}(80 \% \mathrm{RH}$, Dry) calculated with the volume weighted mixing rule, based on the measured GFs from the SMPS.

To obtain the theoretical $f \mathrm{RH}_{\mathrm{ext}}(\% \mathrm{RH}$, Dry) from the GFs the same method as described in Garland et al. (2007) was applied. This method requires the following parameters: (1) the RI of the dry substance, (2) the GF of the substance at a specific RH, and (3) the RI of the humidified substance. The RI of the dry AS was retrieved from the CRD-AS measurements. The hygroscopic GF of AS was determined with humidity-controlled tandem SMPS measurements which were conducted with size-selected AS particles to obtain their dry and humidified size distributions. Using Eq. (3) the GF was consequently calculated. The RI of the humidified AS was calculated using the volume weighted mixing rule:

$$
\begin{aligned}
& n_{\text {mix }}=V_{\text {dry }}^{\text {frac }} n_{\text {dry }}+V_{\text {water }}^{\text {frac }} n_{\text {water }}= \\
& \frac{D_{\text {dry }}^{3} n_{\text {dry }}+\left(D_{\text {wet }}^{3}-D_{\text {dry }}^{3}\right) n_{\text {water }}}{D_{\text {wet }}^{3}}
\end{aligned}
$$




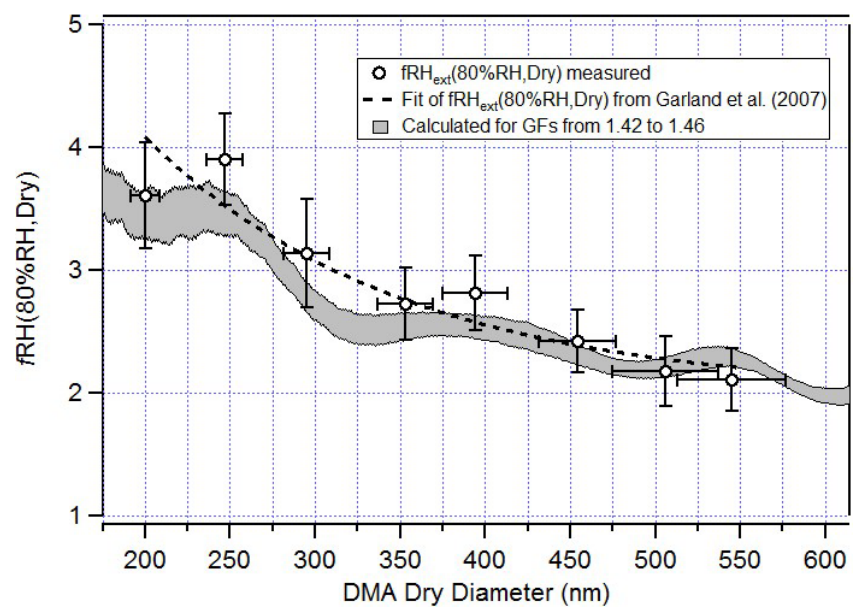

Fig. 2. Measured $f \mathrm{RH}_{\text {ext }}(80 \% \mathrm{RH}$, Dry) as a function of size (solid circles) for pure ammonium sulfate. The dashed line is the exponential fit from the measurements performed by Garland et al. (2007) for ammonium sulfate at the same RH. The shaded area is the calculated $f \mathrm{RH}_{\text {ext }}(80 \% \mathrm{RH}$, Dry) range based on the growth factors measured with the SMPS in this work.

$$
\begin{aligned}
& k_{\text {mix }}=V_{\text {dry }}^{\text {frac }} k_{\text {dry }}+V_{\text {water }}^{\text {frac }} k_{\text {water }}= \\
& \frac{D_{\text {dry }}^{3} k_{\text {dry }}+\left(D_{\text {wet }}^{3}-D_{\text {dry }}^{3}\right) k_{\text {water }}}{D_{\text {wet }}^{3}}
\end{aligned}
$$

where $V_{i}^{\text {frac }}$ is the volume fraction of each component.

The SMPS data was used to determine the volume fraction of water by subtracting the volume fraction of AS (known from the diameter selected by the first DMA) from the total volume of the humidified AS particle (water + AS) known from the (second) humidified SMPS measurements. Applying the volume weighted mixing rule for refractive indices (Eqs. 8.1 and 8.2), with the optical properties of pure AS and water as input, the refractive indices for the humidified aerosol at different RH values were calculated (see Table 1).

Finally, by using Mie scattering calculations (Bohren and Huffman, 1983), the extinction cross sections of the dry and humidified AS aerosol at a wavelength of $532 \mathrm{~nm}$ were calculated with the obtained refractive indices. The ratio of the humidified extinction cross section curve to the dry AS curve gives the theoretical $f \mathrm{RH}_{\text {ext }}(80 \% \mathrm{RH}$, Dry).

The refractive indices used for AS and water at $532 \mathrm{~nm}$ were $m=1.504+i 0.0$ (derived from the dry measurements) and RI of $m=1.335+i 0.0$ (Daimon and Masumura, 2007), respectively.

The reported uncertainties in the measured $f \mathrm{RH}_{\text {ext }}(\% \mathrm{RH}$, Dry) were based on the uncertainty in the RH measurements $( \pm 3 \% \mathrm{RH})$, the SMPS size distributions $(\sim \pm 1 \%)$, and the uncertainty in the measured extinction coefficient from the CRD-AS $(\sim \pm 2 \%)$. The GFs from each diameter were averaged to obtain a range in the theoretical calculations of $f \mathrm{RH}_{\text {ext }}$, represented by the shaded area in Fig. 2. It can be seen in Fig. 2 that the measured $f \mathrm{RH}_{\text {ext }}(80 \% \mathrm{RH}$, Dry) values (every measured value is an average of at least 2 min with an extinction measurement taken by the CRD every $10.1 \mathrm{~s}$ ) are in very good agreement with the $f \mathrm{RH}_{\text {ext }}(80 \% \mathrm{RH}$, Dry) measured by Garland et al. (2007), and with the theoretical calculations. The measured $f \mathrm{RH}_{\text {ext }}(80 \% \mathrm{RH}$, Dry) for AS is that of singly charged particles. The contribution to the extinction cross section from doubly and triply charged particle was subtracted using a complex refractive index of AS $m=1.52+i 0$ (Petterson et al., 2004). The good agreement between the theoretical calculations and the measured values suggests the experimental setup is reliable.

\section{Results}

\subsection{Optical growth of humidified absorbing aerosols}

The size dependence of $f \mathrm{RH}_{\text {ext }}$ at $80 \%$ and $90 \% \mathrm{RH}$ was studied at $532 \mathrm{~nm}$ and $355 \mathrm{~nm}$ wavelengths for substances with different degrees of absorption. The GF values were converted to theoretical $f \mathrm{RH}_{\text {ext }}(\% \mathrm{RH}$, Dry) as described for the $532 \mathrm{~nm}$ AS measurement at $80 \% \mathrm{RH}$. Figure 3 shows the size dependence of $f \mathrm{RH}_{\text {ext }}(80 \% \mathrm{RH}$, Dry) and $f \mathrm{RH}_{\text {ext }}(90 \% \mathrm{RH}$, Dry) for pure AS, IHSS Pahokee Peat, a mixture of AS and nigrosine at a 1:1 molar ratio, and pure nigrosine dye for $80 \%$ (left) and $90 \%$ (right) $\mathrm{RH}$ at $532 \mathrm{~nm}$ (green full markers and patterned shaded area) and $355 \mathrm{~nm}$ (blue open markers and full shaded area). The measured growth factors obtained with the SMPS for each substance are presented in the legend. The reported ranges for the theoretical values (shaded areas in Fig. 3) are based on the values calculated from the lower and upper limits of the uncertainty of the measured GFs.

The measurements for all aerosols at both $\mathrm{RH}$ values and wavelengths are in good qualitative agreement with the calculations. While there are some values that lay outside the shaded area, all substances follow the theoretical trends. The greatest errors can be observed for the mixture of ammonium sulfate and nigrosine at a 1:1 molar ratio. These errors can result from the unknown structure and mixing state of the particles after atomization. Since the volume weighted mixing rule assumes homogenously mixed aerosols, the discrepancies can indicate that in our case the mixture of AS and nigrosine at 1:1 molar ratio is either not an entirely internal structure or homogenous mixture.

The measurement for the Pahokee peat for $355 \mathrm{~nm}$ at $90 \%$ RH could not be completed due to technical issues, the measurement presented was performed at an $\mathrm{RH}=95 \%$ $( \pm 3 \%)$

The ammonium sulfate measurements show that $f \mathrm{RH}_{\text {ext }}(80 \% \mathrm{RH}$, Dry $)$ and $f \mathrm{RH}_{\text {ext }}(90 \% \mathrm{RH}$, Dry $)$ decreases with size non-monotonically. Garland et al. (2007) parameterized $\mathrm{AS}$ at $80 \% \mathrm{RH}$ with an exponential function. However, the theoretical calculations and measurements of 
Table 1. Measured growth factors, average volume weighted refractive indices, and retrieved refractive indices for all substances at $532 \mathrm{~nm}$ and $355 \mathrm{~nm}$, at $80 \%$ and $90 \% \mathrm{RH}$. The retrieved dry refractive indices are also shown.

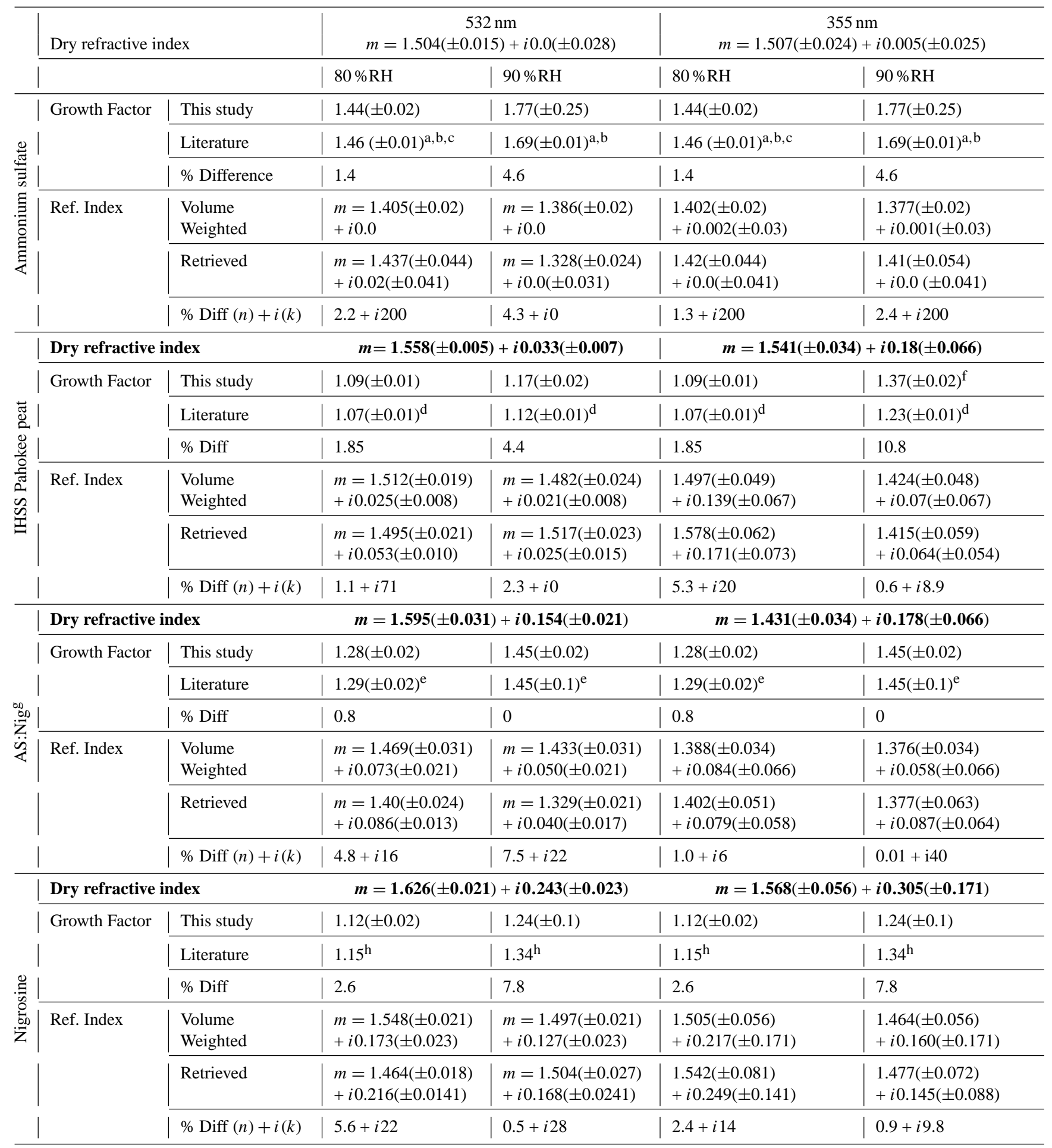

${ }^{\mathrm{a}}$ Gysel et al. (2002); ${ }^{\mathrm{b}}$ Dinar et al. (2008); ${ }^{\mathrm{c}}$ Sjogren et al. (2007); ${ }^{\mathrm{d}}$ Brooks et al. (2004); ${ }^{\mathrm{e}}$ Derived using the ZSR relation; ${ }^{\mathrm{f}}$ Measurement performed at $95 \%$ RH; $\mathrm{g} 1: 1 \mathrm{molar}$ ratio;

${ }^{\mathrm{h}}$ Taken from https://sciencepolicy.colorado.edu/events/rendezvous/2007/posters/II21K.pdf. 

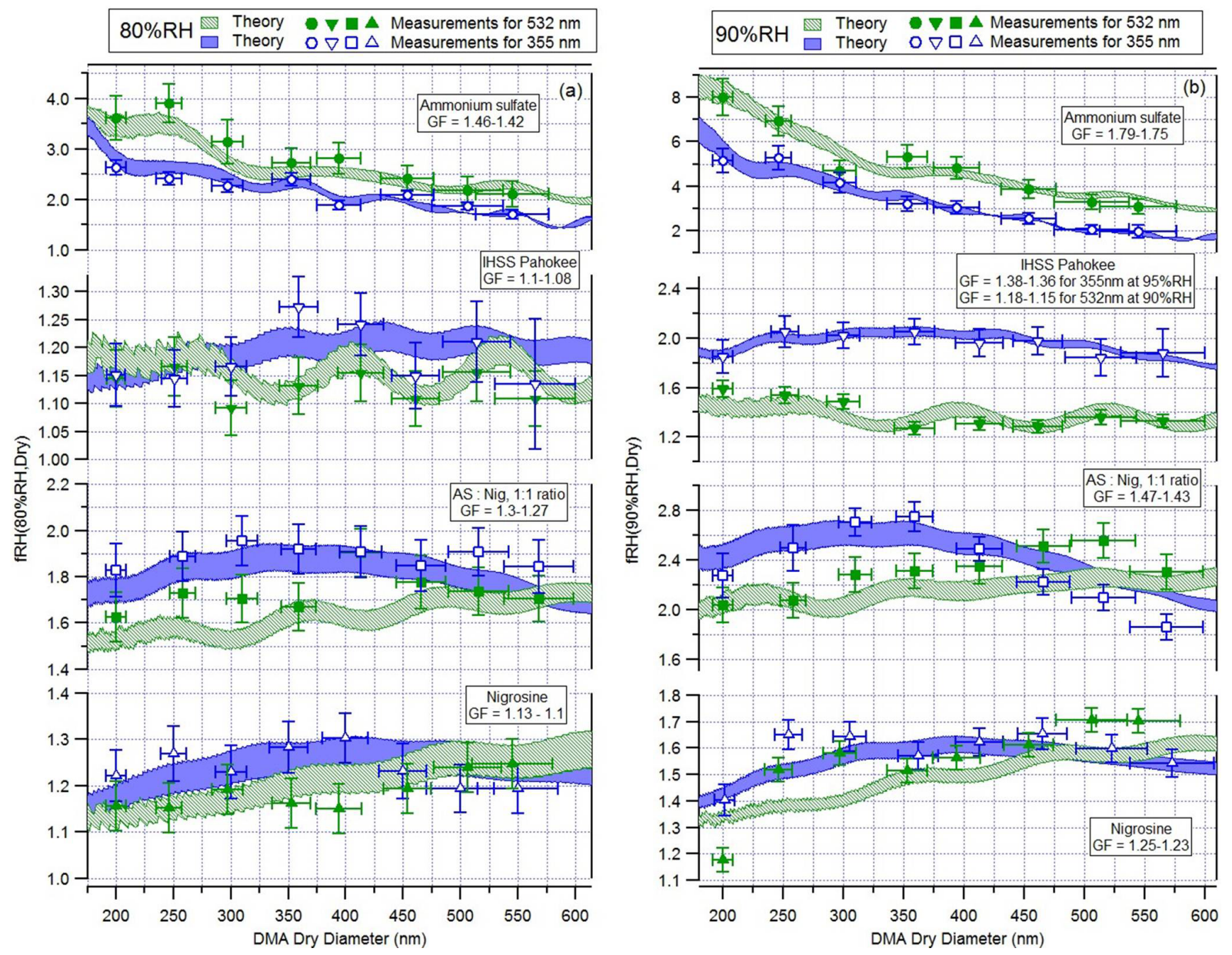

Fig. 3. Size dependence of (a) $f \mathrm{RH}_{\mathrm{ext}}\left(80 \% \mathrm{RH}\right.$, Dry) and (b) $f \mathrm{RH}_{\mathrm{ext}}(90 \% \mathrm{RH}$, Dry), for pure ammonium sulfate (top panel; circles), IHSS Pahokee peat (inverted triangles), the mixture of ammonium sulfate and nigrosine at 1:1 molar ratio (squares), and pure nigrosine (triangles) at $532 \mathrm{~nm}$ (full green markers) and $355 \mathrm{~nm}$ (open blue markers). The shaded areas represent the theoretical size dependence calculated from the measured growth factors from the SMPS. The data for the growth factors are indicated in the legend.

$f \mathrm{RH}_{\text {ext }}$ at both $\mathrm{RH}$ values show that the relationship is not fundamentally exponential as it shows the existence of the Mie resonance structure. Additionally, the $f \mathrm{RH}_{\mathrm{ext}}(80 \% \mathrm{RH}$, Dry) and $f \mathrm{RH}_{\mathrm{ext}}(90 \% \mathrm{RH}$, Dry) values at $532 \mathrm{~nm}$ are greater than at $355 \mathrm{~nm}$. The weak spectral dependence of AS on wavelength might incorrectly lead to expect the same $f \mathrm{RH}_{\text {ext }}(\% \mathrm{RH}$, Dry) curve for both wavelengths. These differences are attributed to the shape of the Mie curves and to the fact that the size parameters $(x=\pi D / \lambda)$ for the diameters measured are larger at $\lambda=355 \mathrm{~nm}$ than at $\lambda=532 \mathrm{~nm}$. For purely scattering substances, the extinction efficiency increases rapidly with size for size parameters smaller than 3, and the slope of this increase is steeper as the real part of the RI is larger. At $355 \mathrm{~nm}$, the initial dry diameters measured have a greater extinction efficiency than at $532 \mathrm{~nm}$, making $f \mathrm{RH}_{\text {ext }}(\% \mathrm{RH}$, Dry) smaller at $355 \mathrm{~nm}$ than at $532 \mathrm{~nm}$.
We also observe in Fig. 3 that the $f \mathrm{RH}_{\text {ext }}$ dependence on size changes from having a non-monotonic decrease with size for purely scattering substances to practically no dependence for absorbing substances. This can also be attributed to the shape of the Mie curves; the extinction efficiency for purely scattering substances increases rapidly as the size increases, causing the observed size dependence. However, as the imaginary component increases, the value of $Q_{\text {ext }}$ for the smaller sizes also increases. An example of this can be seen in Fig. 4, where the value of $Q_{\text {ext }}$ for $200 \mathrm{~nm}$ diameter is smaller for the Pahokee peat $(k \approx 0.05)$ than for nigrosine $(k \geq 0.17)$. In addition, the resonance peaks typical of purely scattering substances are damped with the increase of the imaginary component. The combination of the increase in $Q_{\text {ext }}$ for the smaller sizes and the damping of the resonance peaks for higher imaginary component, cause $f \mathrm{RH}_{\text {ext }}$ for absorbing substances to have practically no size dependence. 

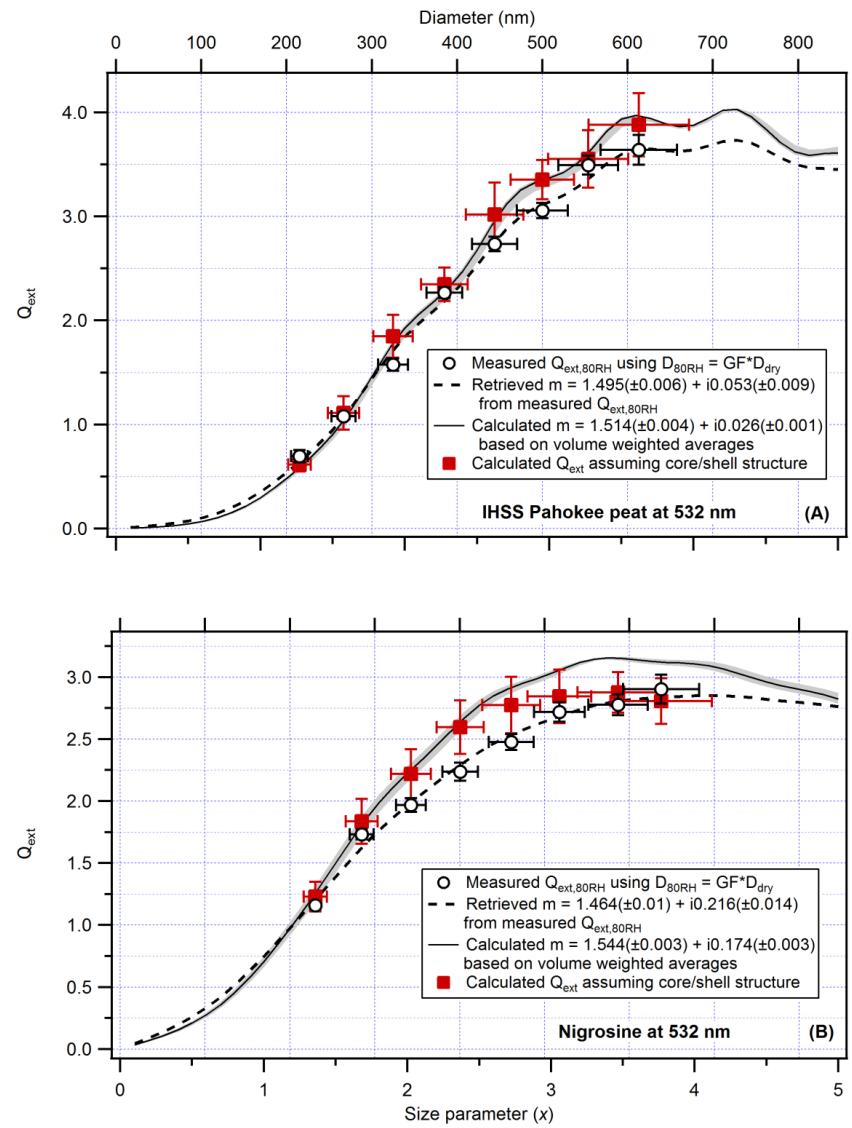

Fig. 4. Extinction efficiency vs. size at $80 \%$ RH for (A) Pahokee peat and (B) Nigrosine aerosol. The open circles represent the mea-

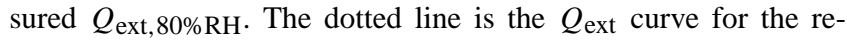
trieved RI from the $Q_{\text {ext, } \% \text { RH }}$ measurements. The solid line shows the calculated $Q_{\text {ext }}$ curve assuming homogeneous mixing and using a volume weighted mixing rule. The shaded area is the range derived from the measured GF uncertainty. The solid squares represent the $Q_{\text {ext }}$ values calculated assuming a core-shell structure.

\subsection{Validation of the volume weighted optical mixing rule}

Figure 3 shows, in general, good qualitative agreement between measurements and theoretical calculations using the measured GFs, assuming homogenous mixing, and using the volume weighted mixing rule to calculate the corresponding complex refractive indices. A quantitative analysis was done by comparing the RI values obtained from the CRD-AS measurements with various Mie-theory based models that assume different mixing states or structures. These calculations may serve as a further verification of the commonly used assumption of homogenously mixed particles at high $\% \mathrm{RH}$ values. To retrieve the RI from the CRD-AS measurements, the extinction efficiency of the humidified aerosols $\left(Q_{\text {ext- } \% \mathrm{RH}}\right)$ was calculated from the measured GF and the extinction coefficient at every diameter. By knowing the value of $Q_{\text {ext }}$ at different diameters for internally mixed aerosols, a refractive index can be retrieved (Lang-Yona et al., 2009; Pettersson et al., 2004; Abo Riziq et al., 2007). Figure 4 shows two examples of the results of the complex RI derivation and comparison performed. Four sets of data of $Q_{\mathrm{ext}}$ versus size at $532 \mathrm{~nm}$ and $80 \% \mathrm{RH}$ for the IHSS Pahokee Peat and nigrosine aerosol are presented: (1) the measured $Q_{\text {ext }, 80 \% \text { RH }}$ values obtained by the CRD-AS and the calculated $D_{80 \% \mathrm{RH}}=\mathrm{GF} \cdot D_{\mathrm{dry}}$, (2) the complex RI retrieved from the $Q_{\text {ext }, 80 \% \mathrm{RH}}$ measurements, using the method described in Abo Riziq et al. (2007), (3) the $Q_{\text {ext }}$ curve for the complex RI calculated assuming homogeneous mixing and applying a volume weighted mixing rule (the shaded area represent the range from the lower and upper limits of the uncertainty of the measured GFs); where the RI for the Pahokee peat and nigrosine aerosols were retrieved from the measurements of the dry aerosol, and the RI value used for water at $532 \mathrm{~nm}$ was $m=1.335+i 0.0$ (Daimon and Masumura, 2007), and (4) the $Q_{\text {ext }}$ values assuming a core-shell structure for each measured diameter. The same analysis was performed for the other aerosols at both $\mathrm{RH}$ values and for both wavelengths. The RI used for water at $355 \mathrm{~nm}$ was $m=1.349+i 0.0$ (Daimon and Masumura, 2007). The results are summarized in Table 1, which also shows a comparison with literature growth factor values (when available), ZSR relation calculations, and the percent difference among the different measurements. The data in the table is presented in order of increasing degree of absorption of the proxy aerosols, from AS (no absorption) to Pahokee Peat to AS:Ng 1:1 and to pure nigrosine (highly absorbing). The retrieved complex refractive indices for most substances at both $\mathrm{RH}$ values are in good agreement with the calculated complex RI from the volume weighted averages; the real part of the RIs are within $7.5 \%$ of each other. There are greater differences in the imaginary parts. However, most values lie within the measurement errors.

For the IHSS Pahokee peat and nigrosine aerosols, there is an overestimation of the retrieved imaginary part with respect to the calculated one with the volume weighted mixing rule at both wavelengths and $\mathrm{RH}$ values. Both substances have a small $\mathrm{GF}(\mathrm{GF}(80 \%)=1.09$ and $\mathrm{GF}(90 \%)=1.17$ for Pahokee peat, and $\mathrm{GF}(80 \%)=1.12$ and $\mathrm{GF}(90 \%)=1.24$ for nigrosine), which raises the question of their internal structures after humidification. It is not clear whether there is a complete dissolution or whether a small shell of water forms around the particles forming a core-shell structure. To explore whether there could be an optical distinction for Pahokee peat and nigrosine, the extinction efficiency as a function of size parameter was calculated separately for each case. For the homogenously mixed case, $Q_{\text {ext-homogeneous }}$ was calculated with the RI obtained from the volume weighted mixing rule. For the core-shell structure, $Q_{\text {ext-core-shell was cal- }}$ culated using the diameter measured after humidification as the total diameter, and the dry diameter selected by the first DMA as the core diameter. The RI of the core was taken 


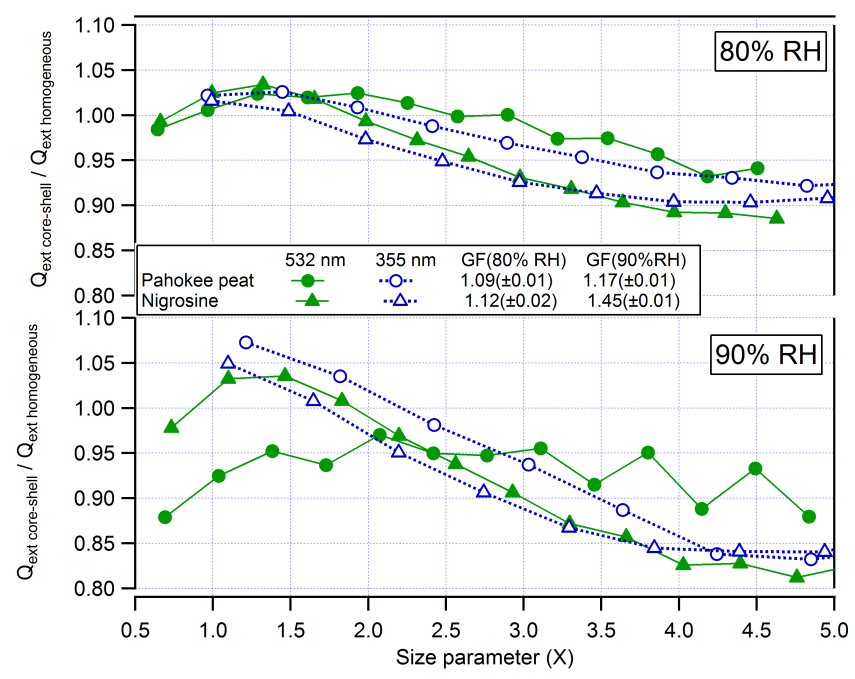

Fig. 5. The ratio of $Q_{\text {ext-core-shell }}$ to $Q_{\text {ext-homogeneous }}$ as a function of size parameter for Pahokee peat (circles) and nigrosine (triangles) at $532 \mathrm{~nm}$ (green) and $355 \mathrm{~nm}$ (blue) at $80 \%$ and $90 \% \mathrm{RH}$. The growth factors for the two substances at $80 \%$ and $90 \% \mathrm{RH}$ are shown in the legend for comparison.

from the dry measurements, and the RI of water was used for the RI of the shell. The codes by Liu et al. (2007a) and Bohren and Hoffmann (1983) were used to calculate $Q_{\text {ext-core-shell }}$ and $Q_{\text {ext-homogeneous, }}$, respectively. Lastly, the ratio of $Q_{\text {ext-core-shell }}$ to $Q_{\text {ext-homogeneous was calculated and }}$ plotted as a function of size parameter for both wavelengths in Fig. 5. From Fig. 5 at $80 \%$ RH, where the Pahokee peat and nigrosine particles only grew $9 \%$ and $12 \%$, respectively, there is less than a $5 \%$ difference between the values obtained with a core-shell structure and those obtained by assuming homogenous mixture for size parameters less than 2.5. For $90 \%$ RH, the differences between the core-shell structure and a homogeneously mixed particle are more noticeable, with up to a $7 \%$ difference for the Pahokee peat. A clear distinction between the two mixing assumptions can be observed at size parameters greater than 3 with lower $Q_{\text {ext }}$ values for a core-shell structure than for a homogeneously mixed case.

Therefore, the nigrosine measurements shown in Fig. 4b, indicate that the difference between the measurements (open circles) and the homogeneous mixing assumption (solid line) is greater at larger size parameters than the core-shell calculation (red solid symbols); which suggest a core-shell structure. However, the measured $Q_{\text {ext }}$ still differs from the core-shell and homogeneous model at the intermediate sizes for nigrosine and it also does not seem to explain adequately the results for Pahokee peat at $80 \%$ RH and $532 \mathrm{~nm}$ (Fig. 4a). Thus we cannot conclusively say whether the core shell model explains fully the result. There is the possibility that partial dissolution of nigrosine or Pahokee peat dissolved into the surrounding water, causing the "coating" to be slightly absorbing. At the same time, the size of the "core" will have shrunk making our original assumptions of size and complex $\mathrm{RI}$ incorrect. Unfortunately, with the precision of the experiments performed in this study it is not possible to examine this hypothesis. However, we do observe from Figs. 4 and 5 that if an aerosol with a GF $<1.15$ is assumed to be homogenously mixed, when in reality its internal structure resembles a core-shell, it will result in an underestimation of the imaginary part of the complex refractive index when the RI is calculated with the volume weighted mixing rule.

\section{Conclusions}

From the laboratory measurements, we see that $f \mathrm{RH}_{\mathrm{ext}}$ at $80 \%$ and $90 \%$ RH could be modeled using Mie theory, the hygroscopic growth factor, and the dry refractive indices of the water soluble absorbing aerosols; there is good agreement between measured and modeled $f \mathrm{RH}_{\mathrm{ext}}$ values as a function of size. We also observe that the $f \mathrm{RH}_{\text {ext }}$ dependence on size changes from having a non-monotonic decrease with size for purely scattering substances to practically no dependence for absorbing substances with an imaginary part greater than zero.

Moreover, the small discrepancies between the retrieved complex RI from direct measurements at 355 and $532 \mathrm{~nm}$ and the complex RI calculated from the volume weighted mixing rule suggest that the volume weighted mixing rule is a good approximation for water soluble aerosols at high $\mathrm{RH}$ conditions, especially for substances with GF $>1.15$. The difference between the derived and calculated real parts of the complex RIs were less than $7.5 \%$ for all substances, wavelengths, and RH values. The obtained imaginary parts for the retrieved and calculated RIs were, in general, in good agreement with each other, and well within the measurement errors of retrieval from pulsed CRD spectroscopy measurements. On the other hand, the homogenous mixture assumption for particles with small GF (less than 1.15) needs to be taken with caution. The discrepancies between the measured $Q_{\text {ext }}$ and the modeled $Q_{\text {ext }}$ using the volume weighted mixing rule, for the low GF substances, Pahokee peat and nigrosine, could not be explained by assuming a core-shell structure with a "pure" substance core and a "pure" water shell. We hypothesize that partial dissolution of the core could make the "coating" slightly absorbing, and shrink the core size of the particle. However, the results show that if a homogeneous mixing is assumed for $\mathrm{GF}<1.15$ the imaginary part of the complex RI can be underestimated.

Acknowledgements. Funding was provided by the Israel Science Foundation (Grant \#196/08) and by FP7-ENV-2010-265148PEGASOS. This research was also funded by the Max Planck Institute internal funding. Y. R. acknowledges support by the Helen and Martin Kimmel Award for Innovative Investigation.

The service charges for this open access publication have been covered by the Max Planck Society. 
Edited by: E. Weingartner

\section{References}

Abo Riziq, A., Erlick, C., Dinar, E., and Rudich, Y.: Optical properties of absorbing and non-absorbing aerosols retrieved by cavity ring down (CRD) spectroscopy, Atmos. Chem. Phys., 7, 15231536, doi:10.5194/acp-7-1523-2007, 2007.

Baynard, T., Garland, R. M., Ravishankara, A. R., Tolbert, M. A., and Lovejoy, E. R.: Key factors influencing the relative humidity dependence of aerosol light scattering, Geophys. Res. Lett., 33, L06813, doi:10.1029/2005g1024898, 2006.

Bohren, C. F. and Huffman, D. R.: Absorption and scattering of light by small particles, Wiley, New York, 1983.

Bond, T. C. and Bergstrom, R. W.: Light Absorption by Carbonaceous Particles: An Investigative Review, Aerosol Sci. Technol., 40, 27-67, 2006.

Brooks, S. D., DeMott, P. J., and Kreidenweis, S. M.: Water uptake by particles containing humic materials and mixtures of humic materials with ammonium sulfate, Atmos. Environ., 38, 18591868, 2004.

Daimon, M. and Masumura, A.: Measurement of the refractive index of distilled water from the near-infrared region to the ultraviolet region, Appl. Opt., 46, 3811-3820, 2007.

Dinar, E., Riziq, A. A., Spindler, C., Erlick, C., Kiss, G., and Rudich, Y.: The complex refractive index of atmospheric and model humic-like substances (hulis) retrieved by a cavity ring down aerosol spectrometer (crd-as), Faraday Discuss., 137, 279295, doi:10.1039/b703111d, 2008.

Dinar, E., Taraniuk, I., Graber, E. R., Anttila, T., Mentel, T. F., and Rudich, Y.: Hygroscopic growth of atmospheric and model humic-like substances, J. Geophys. Res., 112, D05211, doi:10.1029/2006JD007442, 2007.

Erlick, C.: Effective refractive indices of water and sulfate drops containing absorbing inclusions, J. Atmos. Sci., 63, 754-763, 2006.

Fierz-Schmidhauser, R., Zieger, P., Wehrle, G., Jefferson, A., Ogren, J. A., Baltensperger, U., and Weingartner, E.: Measurement of relative humidity dependent light scattering of aerosols, Atmos. Meas. Tech., 3, 39-50, doi:10.5194/amt-3-392010, 2010.

Forster, P., Ramaswamy, V., Artaxo, P., Berntsen, T., Betts, R., Fahey, D. W., Haywood, J., Lean, J., Lowe, D. C., Myhre, G., Nganga, J., Prinn, R., Raga, G., Schulz, M., and Dorland, R. V.: Changes in Atmospheric Constituents and in Radiative Forcing., in: Climate Change 2007: The Physical Science Basis. Contribution of Working Group I to the Fourth Assessment Report of the Intergovernmental Panel on Climate Change, edited by: Solomon, S., Qin, D., Manning, M., Chen, Z., Marquis, M., Averyt, K. B., Tignor, M., and Miller, H. L., Cambridge University Press, Cambridge, United Kingdom and New York, NY, USA, 2007.

Garland, R. M., Ravishankara, A. R., Lovejoy, E. R., Tolbert, M. A., and Baynard, T.: Parameterization for the relative humidity dependence of light extinction: Organic-ammonium sulfate aerosol, J. Geophys. Res., 112, D19303, doi:10.1029/2006JD008179, 2007.
Gysel, M., Weingartner, E., and Baltensperger, U.: Hygroscopicity of aerosol particles at low temperatures. 2. Theoretical and experimental hygroscopic properties of laboratory generated aerosols, Environ. Sci. Technol., 36, 63-68, doi:10.1021/es010055g, 2002.

Hasenkopf, C. A., Freedman, M. A., Beaver, M. R., Toon, O. B., and Tolbert, M. A.: Potential climatic impact of organic haze on early earth, Astrobiology, 11, 135-149, doi:10.1089/ast.2010.0541, 2011.

Haywood, J. M., Roberts, D. L., Slingo, A., Edwards, J. M., and Shine, K. P.: General circulation model calculations of the direct radiative forcing by anthropogenic sulfate and fossilfuel soot aerosol, J. Climate, 10, 1562-1577, doi:10.1175/15200442(1997)010<1562:GCMCOT>2.0.CO;2, 1997.

IPCC: Climate Change 2007: The Physical Science Basis. Contribution of Working Group I to the Fourth Assessment Report of the Intergovernmental Panel on Climate Change, edited by: Solomon, S., Qin, D., Manning, M., Chen, Z., Marquis, M., Averyt, K. B., Tignor, M., and Miller, H. L., Cambridge University Press, Cambridge, United Kingdom and New York, NY, USA, 996 pp., 2007.

Koren, I., Remer, L. A., Kaufman, Y. J., Rudich, Y., and Martins, J. V.: On the twilight zone between clouds and aerosols, Geophys. Res. Lett., 34, L08805, doi:10.1029/2007g1029253, 2007.

Lang-Yona, M., Rudich, Y., Segre, E., Dinar, E., and Abo-Riziq, A.: Complex refractive indices of aerosols retrieved by continuous wave-cavity ring down aerosol spectrometer, Anal. Chem., 81, 1762-1769, doi:10.1021/ac8017789, 2009.

Lewis, K. A., Arnott, W. P., Moosmüller, H., Chakrabarty, R. K., Carrico, C. M., Kreidenweis, S. M., Day, D. E., Malm, W. C., Laskin, A., Jimenez, J. L., Ulbrich, I. M., Huffman, J. A., Onasch, T. B., Trimborn, A., Liu, L., and Mishchenko, M. I.: Reduction in biomass burning aerosol light absorption upon humidification: roles of inorganically-induced hygroscopicity, particle collapse, and photoacoustic heat and mass transfer, Atmos. Chem. Phys., 9, 8949-8966, doi:10.5194/acp-9-8949-2009, 2009.

Liu, L., Wang, H., Yu, B., Xu, Y., and Shem, J.: Improved algorithm of light scattering by a coated sphere, China Part., 5, 230-236, 2007a.

Liu, X., Penner, J. E., Das, B., Bergmann, D., Rodriguez, J. M., Strahan, S., Wang, M., and Feng, Y.: Uncertainties in global aerosol simulations: Assessment using three meteorological data sets, J. Geophys. Res., 112, D11212, doi:10.1029/2006jd008216, 2007b.

Novakov, T., Hegg, D. A., and Hobbs, P. V.: Airborne measurements of carbonaceous aerosols on the East Coast of the United States, J. Geophys. Res., 102, 30023-30030, 1997.

Miles, R. E., Rudic, S., Orr-Ewing, A. J., and Reid, J. P.: Influence of Uncertainties in the Diameter and Refractive Index of Calibration Polystyrene Beads on the Retrieval of Aerosol Optical Properties Using Cavity Ring Down Spectroscopy, J. Phys. Chem., 114, 7077-7084, doi:10.1021/jp103246t, 2010.

Pettersson, A., Lovejoy, E. R., Brock, C. A., Brown, S. S., and Ravishankara, A. R.: Measurement of aerosol optical extinction at $532 \mathrm{~nm}$ with pulsed cavity ring down spectroscopy, J. Aerosol Sci., 35, 995-1011, doi:10.1016/j.jaerosci.2004.02.008, 2004.

Petzold, A., Weinzierl, B., Huntrieser, H., Stohl, A., Real, E., Cozic, J., Fiebig, M., Hendricks, J., Lauer, A., Law, K., Roiger, A., Schlager, H., and Weingartner, E.: Perturbation of the European 
free troposphere aerosol by North American forest fire plumes during the ICARTT-ITOP experiment in summer 2004, Atmos. Chem. Phys., 7, 5105-5127, doi:10.5194/acp-7-5105-2007, 2007.

Reddy, M. S., Boucher, O., Balkanski, Y., and Schulz, M.: Aerosol optical depths and direct radiative perturbations by species and source type, Geophys. Res. Lett., 32, L12803, doi:10.1029/2004GL021743, 2005.

Schwartz, S. E. and Buseck, P. R.: Absorbing Phenomena, Science, 288, 989-990, 2000.

Sjogren, S., Gysel, M., Weingartner, E., Baltensperger, U., Cubison, M. J., Coe, H., Zardini, A. A., Marcolli, C., Krieger, U. K., and Peter, T.: Hygroscopic growth and water uptake kinetics of two-phase aerosol particles consisting of ammonium sulfate, adipic and humic acid mixtures, J. Aerosol Sci., 38, 157-171, doi:10.1016/j.jaerosci.2006.11.005, 2007.
Stokes, R. H. and Robinson, R. A.: Interactions in aqueous nonelectrolyte solutions. I. Solute-solvent equilibria, J. Phys. Chem., 70, 2126-2130, 1966.

Streets, D. G., Wu, Y., and Chin, M.: Two-decadal aerosol trends as a likely explanation of the global dimming/brightening transition, Geophys. Res. Lett., 33, L15806, 10.1029/2006GL026471, 2006.

Tripathi, S. N., Dey, S., Tare, V., and Satheesh, S. K.: Aerosol black carbon radiative forcing at an industrial city in northern India, Geophys. Res. Lett., 32, L08802, doi:10.1029/2005GL022515, 2005.

Wiedensohler, A.: An approximation of the bipolar charge distribution for particles in the submicron size range, J. Aerosol Sci., 19, 387-389, 1988. 